\title{
17
}

\section{Strategic Performance of the Production System in a Machine-Tool Building Company}

J.M. Goenaga and C. Goikoetxea ${ }^{\mathrm{a}}$

'Design and Management of Production Systems Department, Ikerlan S. Coop., 2 J.M. Arizmendiarrieta, 20500 Mondragon, Spain

This position paper presents part of the work carried out in an application case-study ${ }^{*}$. The global project falls within the framework of what is known as Business Processes Redesign. To be exact, a strategic analysis of the production system of a machine tool building company has been performed.

\section{THE COMPETITIVE THREESOME}

The starting point of the work was the competitive threesome composed of the Company's Strategy, The Market and the Production System. The Corporate Strategy represents how the company wants to be the best in. The Production System represents how the strategy has been implemented. The third component, Market-Customer, represents how the customer perceives the company's way of being the best.

\section{Competitive threesome}

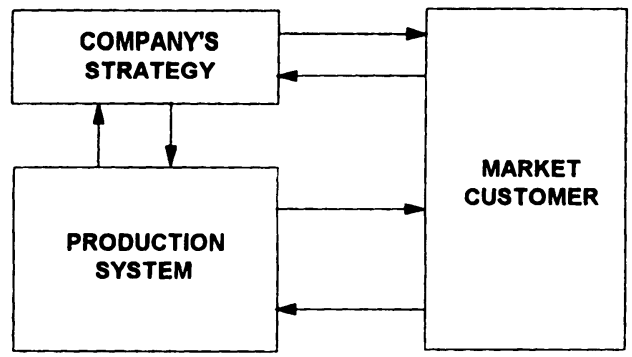

Figure 1. The competitive threesome

\footnotetext{
- We would like to thank Danobat S.Coop. for its active participation as test bed and Profs. Josep Riverola and Beatriz Mufioz-Seca at I.E.S.E. (Madrid) for its collaboration in the project. We also give gratitude to the Unidad de Estrategia Tecnológica (S.P.R.I. - Basque Government) for its financial support of the project.
} 
The three components are related to each other by how the customer perceives the product-service offered by the company. The General Management of the company must define a long term strategy and objectives that have first, to be understood and assumed by the Production System in order to ensure that the product-service gets from the customer the perception it was expecting.

\section{DEFINING THE STRATEGY}

This customer perception game allows the company to select the desired way of competing. The game starts from the definition of the long term strategy of the company. The strategy must be defined by using production system related terms.

Several generic ways of competition such as cost, flexibility, innovation... have been defined by different authors. But their generic being makes it difficult to match them to the specific nature of each company because:

-A company usually competes in different market segments.

- Each market segment imposes its specific benchmark.

- These benchmarks may not be synergetic.

For this reasons the approach taken by the project has been to define objective criteria that allow the definition of what we call the competitiveness profile of the company. In order to define the competitive criteria the following must be considered:

* The long term strategy and objectives of the company.

* The parameters by which the customer perceives how the company wants to be the best.

\subsection{The Five Criteria}

The criteria defined in the project are:

CONSISTENCY: Reflects the degree of compliance between what was agreed about the production of each order and what has really happened. Two dimensions have been selected to be measured: Price/Cost (variability between the estimated and real price/cost) and Time (variability between the estimated and real time consumed from the approval of the order and the delivery of the machine).

TECHNICAL CAPACITY - MARKET SCOPE: This criteria aims to measure the wideness of the company's offer range. Two aspects defining and measuring this criteria in this particular application have been: the percentage of the objective market that the company's offer copes with and the level of parameterisation of machine component parts.

INNOVATION: The aim is to measure the implementation of new technologies (non-existent technologies in any machine tool built by the company before). The criteria measures the number of innovations introduced per year. 
PRICE - COST: Cost measures cannot be compared with competitors' figures, so the approach has been to measure actual cost performance and to establish cost reduction objectives.

DELIVERY TIME: The time needed to produce a machine tool. The time between the order arrival and machine delivery is measured.

\subsection{Stablishing the competitive profiles}

To this extent, we have defined the competitiveness criteria. Now, it is time to determine the competitive profiles of the company. To do this task, a series of interviews with company's staff and customers were carried out. As a result, a range of values for each criteria was defined, with the highest level being that of the leading competitor while the lowest level is the minimum acceptable level (or viceversa if the low level is the optimum). So, it is a relative evaluation approach.

\section{COM PETITIVE PROFILES}

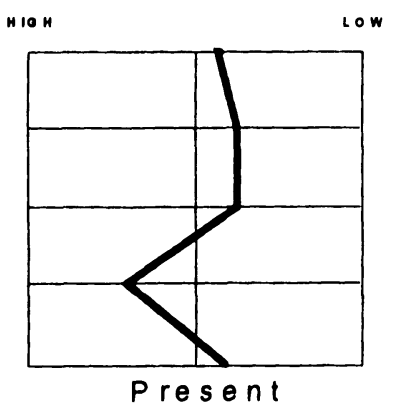

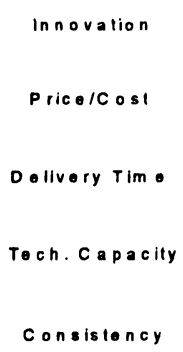

Consistoncy

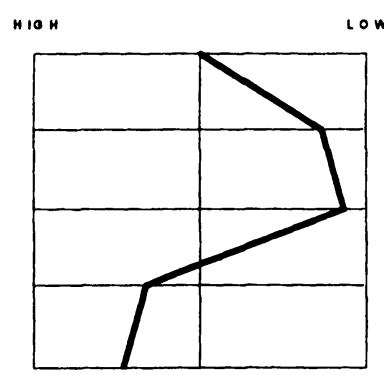

Future

Figure 2. Competitive profiles

The difference between the shapes of both the present and future profiles indicates the direction of improvements, and the criteria identify the nature of the actions to be carried out. The next step is to identify the critical activities of the business and to determine the specific actions to be carried out in order to obtain the desired competitive profile, but this is a very detailed task, the explanation of which this position paper does not aim to go into.

\section{MONITORING IMPROVEMENTS}

Once the critical activities have been identified and improvement actions defined and implemented, monitoring of improvements is required. It is vital to check how our actions contribute to improve our competitiveness. This monitoring task requires the definition of real parameters related to the production system that show the system performance in accordance with 
strategic goals. The relationship between the parameters and the strategy is built by means of the competitive criteria. Some of the parameters defined in this application are shown in table 1.

\begin{tabular}{|l|l|}
\hline PARAMETER & \multicolumn{1}{|c|}{ DESCRIPTION } \\
\hline P1 & Percentage of parts in the objective market we can offer \\
\hline P2 & Number of parametric programs in operation \\
\hline P3 & Number of design hours worked in each order \\
\hline P4 & Mean deviation of parameter P3 by each machine family \\
\hline P5 & Mean of P3 by each machine family \\
\hline P6 & Design costs per month and order \\
\hline P7 & Purchasing costs per month and order \\
\hline P8 & Final Assembly costs per month and order \\
\hline P9 & Machine setup costs per month and order \\
\hline P10 & Machining tests costs per month and order \\
\hline P11 & Total cost = P6+P7+P8+P9+P10 \\
\hline P12 & Mean deviation of the difference between real and estimated cost by \\
& each machine family \\
\hline P13 & Mean deviation of machines costs by each machine family \\
\hline P14 & Mean machine cost by each family \\
\hline P15 & Time worked per phase and order \\
\hline P16 & Date of first jobs per phase and order \\
\hline P17 & Date of last jobs per phase and order \\
\hline P18 & P15/(P17-P16) \\
\hline P19 & Mean deviation of P15 per phase and machine family \\
\hline P20 & Mean of P15 per phase and machine family \\
\hline P21 & Delivery date - order arrival date \\
\hline P22 & Delivery date - order launch date \\
\hline P23 & Mean deviation of P21 per machine family \\
\hline P24 & Mean of P21 per machine family \\
\hline P25 & Mean deviation of P22 per machine family \\
\hline P26 & Mean of P22 per machine family \\
\hline
\end{tabular}

Table 1. Monitoring parameters 


\section{CONCLUSIONS}

To conclude let's point out the main aspects to be taken into account:

1. A globally balanced multicriteria approach has been applied. A company may compete in several market segments and each one influences the criteria with different weights. A balanced profile must be stablished.

2. The strategy as well as the customer perception must be stated in terms of production system parameters or variables.

3. We must fit the customer perception to our strategy, we must produce goods or services that are perceived by our customers as we want them to be. We therefore need to match the improvement actions to the differences between the market perception and our strategy.

4. These parameters must be easily measured to allow monitoring 